\title{
Economic Aspects Analysis in Calculation and Application of the Urban Environment Quality Index
}

\author{
$D M$ Suvorov $^{1, *}, L A$ Suvorova, and $T V$ Baibakova \\ Vyatka State University, Kirov, Russia
}

\begin{abstract}
The goal of the study is to make a comparative analysis of the dynamics of indices of economic indicators and sufficiency indicators used to calculate an urban environment quality index of a Russian municipality. The city of Kirov, Russia, was taken as a sample for the study, which went on from 2012 through 2018. The analysis demonstrated practically no statistically significant correlations in the dynamics of indices of individual subgroups of indicators, as well as in the dynamics of indices of individual indicators, although with a few exceptions. The results of the study confirm the need to improve the methodology of calculating the integral indices of cities and regions. These indices are related to urban ecology, quality of life, and sustainable development issues. The results also demonstrated the inadequacy of such tools for systematic and comprehensive international analysis of today urbanization problems.
\end{abstract}

\section{Introduction}

The issue of sustainable development of cities and regions has been the mainstream of world urbanism for several decades [1, 2]. Problems and the approaches tackling them are extremely diverse. They cover, first of all, economic, nature-and-ecological, social (including demographic), town-planning (including land use), infrastructure (energy, transportation, housing and communal) aspects, often interwoven and interlinked [29]. During the previous three decades the prevailing approach was based mainly on ensuring long-term environmental and ecological sustainability $[1,5,9]$, however recent research done in developed countries (the USA, Canada, European countries), as well as in the developing ones (China, Indonesia, Iran, etc.) has demonstrated a certain bias toward ensuring economic, social and infrastructural development of cities and towns, provided the environmental and ecological situation does not deteriorate [2, 4-7].

The sustainable urban development research tends to mostly calculate various integral indices (often ratingforming ones), which give relative assessment of an urban territory's condition or its development sustainability. Such indices can directly characterize not only the urban development sustainability degree, but also the quality of life of the population, the urban environment quality, and the liveness (survivability) of urban infrastructure [10-16]. However, they all share many similar indicators, the dynamics of the corresponding indices and their components can always give an assessment of the degree of of urban development sustainability in its entirety $[5,7,9,12,14$, $16,17]$. At the same time, it should be noted that such indices contain an environmental-and-ecological element and, therefore, they can be essentially defined as urbanecological in a broad sense. Such integral indices, regardless of the calculation methods used and the valuation conditions for indices of individual indicators, cannot be absolute. They are essential mainly when compared with indices for other cities, as well as from the point of view of their dynamics, which makes it possible to evaluate the development sustainability. This approach is consistent with the current UN agenda on sustainable urban development [18].

Based on the approaches proposed in [11, 13], the authors of this article developed a method for calculating the urban environment quality index (UEQI) for a municipality. The method was presented in [19], was tested for the city of Kirov (Russia). In this study, based on the city's UEQI dynamics calculated for 2012-2018, we consider possible relationships among individual indicators belonging to different subgroups of the same name groups, namely, the economic indicators subgroups and the urban environment quality sufficiency indicators subgroups. In work [19], instead of the name "sufficiency indicators", which was introduced for the purposes of this study, is used the name "indicators of provision", and as an abbreviation for the integral index, DIUEQ is used instead of UEQI.

Thus the goal of the study is to make a comparative analysis of the dynamics of indices of economic indicators and sufficiency indicators used to calculate an urban environment quality index based on the identification of paired correlations among the indices of the corresponding indicators in retrospect.

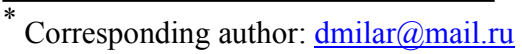




\section{Research Methods}

The method for calculating virtually all integral indices in urban studies is based on the UN-proposed city prosperity index (CPI), which is described in detail in $[11,13]$. The method of calculating the UEQI in question also corresponds to this approach and is described in some detail in [19], where the UEQI values are given when this method was tested for the city of Kirov, Russia. It should be noted that in the UEQI composition we isolated 4 groups of indicators, namely: the first - "Safety and ecology of the urban environment", the second - "Architectural and landscape part of the urban environment and housing", the third "Social environment and public leisure infrastructure environment", and the fourth - "Engineering and transport infrastructure of the urban environment" [19, 20]. Each group includes same three subgroups: sufficiency indicators ("indicators of provision" according to the terminology used in [19]), economic indicators and sociological evaluation indicators, however, the retrospective data are available only on the indicators of the first two subgroups. A sociological survey and the evaluation of indicators of the third subgroup were once carried out while testing the method at the end of 2017. The survey made it possible to significantly refine the UEQI in comparing the index values of those objective and subjective indicators, which reflect similar qualitative characteristics of the urban environment. The study further confirmed the correctness of the valuation of certain sufficiency indicators.

All indicators were converted into indices by method [13] through linear valuation. Index value of 0.0 corresponds to the worst possible value of each indicator, the index value of 1.0 means the best value (for example, normative one). All sufficiency indicators and economic indicators were calculated primarily on the basis of official statistics, as for the economic indicators, the data were taken mainly from the accounts on the city budget expenditures for each year of the period. An important principle in UEQI calculation is the balance of groups and subgroups in the number and value of indicators, which implies a priori equilibrium of indicators' indices in subgroups, subgroups' indices in groups, and group indices when calculating the UEQI, which leads to an easy-to-do calculation of composite indices as arithmetic averages as implemented in [19, 20], and in many international methods [10, 12-13].

Within each of the considered groups, economic indicators and sufficiency indicators were determined through expert assessments, thus, it became possible to a priori assume certain correlations among the indicators. The total number of indicators in all 4 groups were 36 sufficiency indicators and 24 economic indicators.

Then a series of index values were calculated for the indicators representative of the city of Kirov over the 2012-2018 period. Next, using conventional EXCEL tools, we drew graphical dependencies of pairwise comparison of each of the economic indicators with each of the a priori corresponding sufficiency indicator, and defined the parameters of the linear coupling equation and the pair correlation coefficient between them. Those correlations were drawn in two ways: first, without shifting the compared series by year; second offsetting the indices of sufficiency indicators by one year ahead as compared with the indices of economic indicators, which made it possible to take into account the possible inertia (no more than a year) of the economic changes affecting the sufficiency indicators' values. The economic indicators that were indexed in a monetary form (usually in rubles per capita per year) for 2013-2016 and for 2018, were adjusted to 2017 prices through discounting by the value of the GDP deflator index in Russia for the corresponding years.

The existence of a possible relationship between an economic indicator and the sufficiency indicator compared with is suggested by two parameters: a positive linear correlation between indicator indices close to 1.0, and a high pair correlation coefficient. Considering the fact that the amount of data in the compared series is small (6 pairs for comparison without offset and 5 pairs for a 1 year offset), the pair correlation coefficient exceeding 0.8 should be considered statistically significant for this study. Presence (or absence) and the nature of correlations among indicator indices can be the basis for identifying and analyzing inconsistencies (disproportions, imbalances, disparities) of urban development in accordance with the general methodological approach to minimizing inconsistencies suggested and substantiated in [21].

\section{Analysis Results and Discussion}

A retrospective analysis of indices of economic indicators showed their high volatility for each of the 4 subgroups. As an example, Figure 1 shows the dynamics of some economic indicator indices of group 4 for the city of Kirov, Russia.

Figure 1 reflects a sharp drop of 4.3.1 indicator's index "Per capita municipal budget spendings on communal services" for 2017-2018; a sharp rise of 4.3.5 indicator's index "Per capita municipal budget spendings on roads" and pronounced fluctuations of 4.3.3 indicator's index "Per capita municipal budget spendings on public transportation” for 2017-2018.

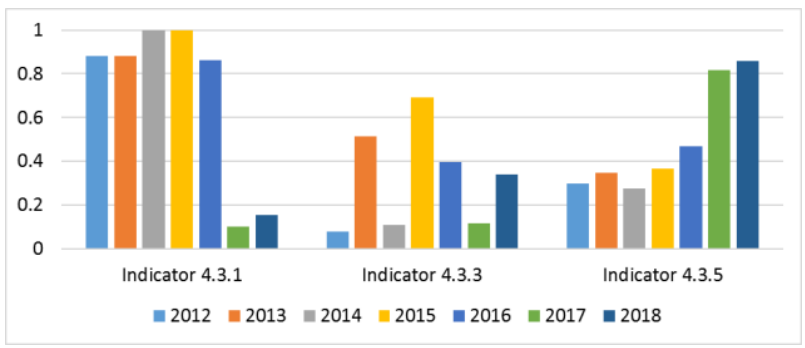

Fig. 1. Dynamics of some economic indicator indices of group 4 for 2012-2018.

Further, Table 1 and Figures 2 and 3 illustrate some results of a comparative correlation analysis of indices of certain economic indicators and sufficiency indicators of similar groups for the city of Kirov for 2012-2017. For indicators that are not given in Table 1, there is no 
Table 1. Results of a Correlation Analysis of Indices of Sufficiency Indicators and Certain Economic UEQI Indicators for the City of Kirov for 2012-2017.

\begin{tabular}{|l|l|c|c|}
\hline \multicolumn{1}{|c|}{$\begin{array}{c}\text { Number and the name of a sufficiency } \\
\text { indicator }\end{array}$} & \multicolumn{1}{|c|}{$\begin{array}{c}\text { Number and name of the compared } \\
\text { economic indicator }\end{array}$} & $\begin{array}{c}\text { No off-set } \\
\text { correlation } \\
\text { coefficient }\end{array}$ & $\begin{array}{c}\text { 1 year off-set } \\
\text { correlation } \\
\text { coefficient }\end{array}$ \\
\hline $\begin{array}{l}\text { 1.1.5.The crime rate per } 10 \text { thousand } \\
\text { population }\end{array}$ & $\begin{array}{l}1.3 .1 \text { Per capita municipal budgetary } \\
\text { expenditures for public security and law } \\
\text { enforcement }\end{array}$ & 0.1903 & 0.1659 \\
\hline $\begin{array}{l}\text { 2.1.4. Tree-covered area in the total land area } \\
\text { within city limits }\end{array}$ & $\begin{array}{l}2.3 .3 \text { Per capita municipal budgetary } \\
\text { expenditures for urban improvement }\end{array}$ & 0.3296 & 0.8165 \\
\hline $\begin{array}{l}\text { 2.1.6. City Illumination rate } \\
\text { 3.1.5. Share of municipal educational } \\
\text { institutions students studying in the second } \\
\text { third) shift }\end{array}$ & $\begin{array}{l}3.3 .1 . \quad \text { Per capita municipal budgetary } \\
\text { expenditures for urban improvement }\end{array}$ & 0.2607 & 0.1685 \\
\hline $\begin{array}{l}\text { 4.1.2. Length of local public motor roads not } \\
\text { meeting regulatory requirements }\end{array}$ & $\begin{array}{l}4.3 .5 \text { Per capita municipal budgetary } \\
\text { expenditures for roads and road facilities }\end{array}$ & 0.9153 & 0.7715 \\
\hline $\begin{array}{l}\text { 4.1.3. Per capita urban public passenger } \\
\text { traffic }\end{array}$ & $\begin{array}{l}4.3 .3 . \quad \text { Per capita municipal budgetary } \\
\text { expenditures for public transportation }\end{array}$ & 0.1273 & 0.6422 \\
\hline
\end{tabular}

correlation with the sufficiency level value exceeding 0.1 . Based on the obtained results, we can assume that there is a rather noticeable correlation only between indicators 2.1.4 and 2.3.3, 3.1.5 and 3.3.1, as well as 4.1.2 and 4.3.3. If the relationship between the treecovered areas and the urban improvement budget expenditures is quite understandable, the other two dependencies shown in Figure 2 and Figure 3 need commenting on (In Figures 2 and 3: Time period for the city of Kirov for 2012-2017; $y=f(x)$ is the equation of linear dependence between indices (straight line); $\mathrm{R}^{2}$ is the pair correlation coefficient).

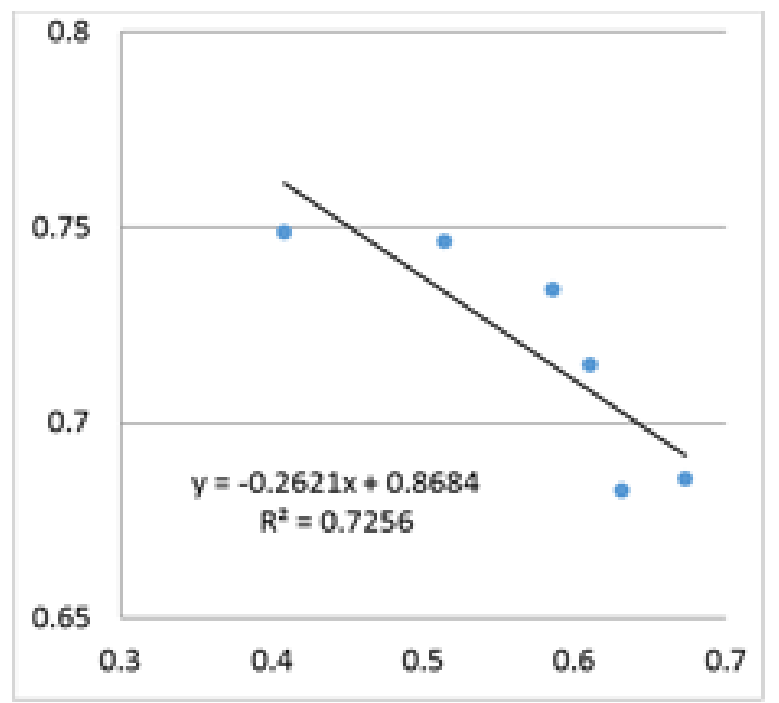

Fig. 2. Index of the share of municipal educational institutions students studying in the second (third) shift (ordinate, y-axis), depending on the per capita municipal budgetary expenditures for education (abscissa, $\mathrm{x}$-axis).

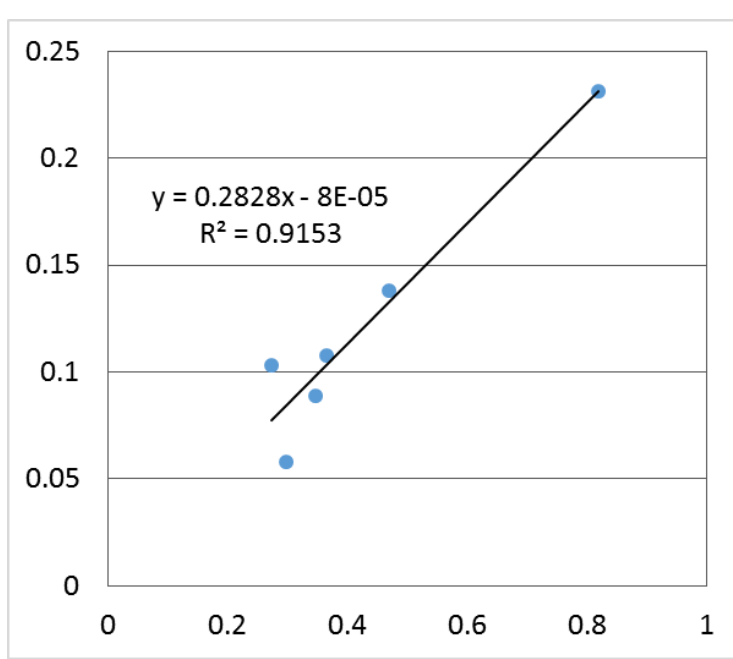

Fig. 3. Index of the length of local public motor roads not meeting regulatory requirements (ordinate, y-axis), depending on the per capita municipal budgetary expenditures for roads and road facilities (abscissa, $\mathrm{x}$-axis).

In 2012-2017 the share of the city's motor roads not meeting the regulatory requirements was dropping steadily (from $84.2 \%$ in 2012 to $69.2 \%$ in 2017), hence the rise of this indicator's index. In this period the per capita budgetary expenditures for roads and road facilities rose from 1788 to 4909 rubles, which resulted in the increase of that indicator's index as well. It should be emphasized that the road expenditures increased due to drastic budget cuts in other spheres, primarily in housing and communal utilities (Figure 1).

As for the share of municipal educational institutions students studying in the second (third) shift, it rose in 2012-2016 from 26.6 to $33.1 \%$ and only in 2017 it began to decline slightly, however, the annual per capita budget expenditures for education during this period increased from 8.5 to 11.4 thousand rubles (in comparable prices). This inverse correlation is not natural and stable; it reflects the fact that in that period the proportion of students among the population of the city significantly 
increased, meanwhile the construction of new educational institutions lagged behind the growth in the number of students. At the same time, the funding met the established federal standards per a student, rather than per a city resident.

The dynamics of the UEQI components for the city of Kirov by subgroups of sufficiency indicators, by subgroups of economic indicators and for the UEQI in general (excluding sociological indicators, as they were determined only once, in 2017) are presented in Figure 4.

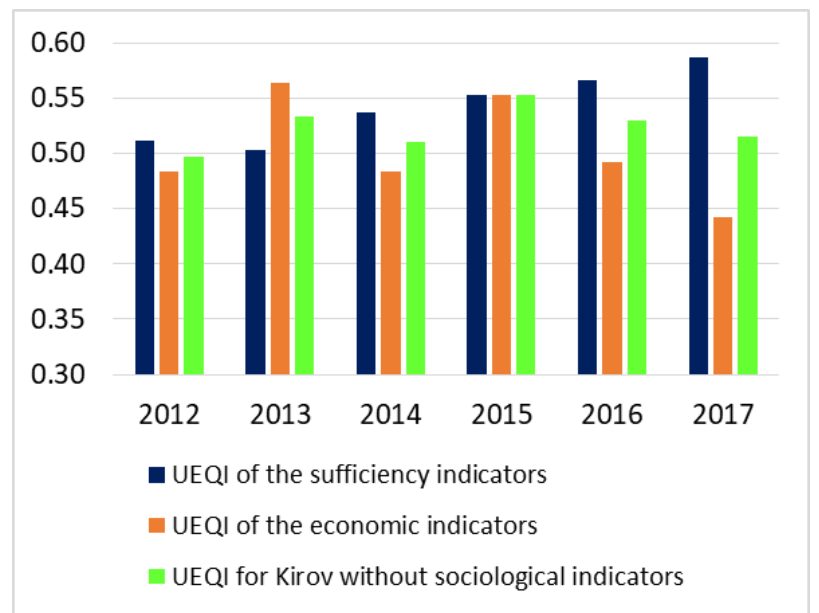

Fig. 4. UEQI dynamics and that of its components for the city of Kirov for 2012-2017.

It is obvious that in that period the UEQI of the sufficiency indicators demonstrated a fairly steady growth, while the UEQI of the economic indicators showed extremely unstable dynamics with a tendency to decrease, which led to fluctuations in UEQI as a whole, with two peaks - in 2013 and 2015 (Figure 4).

\section{Conclusion}

The analysis performed in this study revealed significant inconsistencies in the budget planning for the development of Kirov, which is manifested in an unbalanced and disproportionate approach to both urban planning and the actual implementation of those plans. Such inconsistencies, on the one hand, lead to explicit volatility of the city's certain budget indicators and indices of those indicators, which are taken into account when calculating the UEQI. On the other hand, the inconsistencies prohibit effective use of budgetary funds in a number of areas, which is manifested, inter alia, in the absence of significant correlations among those economic indicators and sufficiency indicators where such links should be assumed a priori.

This analysis enables us to suggest that the existing method, used in $[19,20]$, of calculating the municipality UEQI should be improved. We suggest that special economic indicator subgroup in each of the groups should be discarded; or that economic characteristics should be introduced into sufficiency indicator groups, or that an additional group within the UEQI should be created, and named "The Economy of the Urban
Environment," for instance, as it is the fact in many cases [10-13]. The second option seems to be preferable; however, the composition of the indicators for this group should be further substantiated.

The results of the study confirm the need to improve the methodology of calculating the integral indices of cities and regions of countries. These indices evaluate urban environment quality and the cities/regions sustainability. The results also demonstrated inadequacy of such tools for systematic and comprehensive analysis of today urbanization problems. The study has also revealed the need for a wide international cooperation and generalization of the international thought on the matter.

\section{References}

[1] T. Yigitcanlar, M. Kamruzzaman, Planning, development and management of sustainable cities: A commentary from the guest editors, in Sustainability, 7, 11, 14677-14688 (2015) [Electronic resource]. Available at: https://eprints.qut.edu.au/89930/.

[2] T. Yigitcanlar, M. Kamruzzaman, Investigating the interplay between transport, land use and the environment: a review of the literature, Int. J. Environ. Sci. Technol, 11, 2121-2132 (2014). DOI: $10.1007 / \mathrm{s} 13762-014-0691-\mathrm{z}$.

[3] G. Noto, Combining system dynamics and performance management to support sustainable urban transportation planning, in Journal of Urban and Regional Analysis, IX, 1, 51-71 (2017).

[4] J. Rajaonson, G.A. Tanguay, A sensitivity analysis to methodological variation in indicatorbased urban sustainability assessment: a Quebec case study in Ecological Indicators, 83, 122-131 (2017). DOI: 10.1016/j.ecolind.2017.07.050.

[5] M. Prakash, K. Teksoz, J. Espey, J. Sachs, M. Shank, G. Schmidt-Traub, Achieving A Sustainable Urban America, The U.S. Cities Sustainable Development Goals Index, 36 (2017) [Electronic resource]. Available at: http://unsdsn.org/wpcontent/uploads/2017/08/US-Cities-SDG-Index2017.pdf.

[6] A. Pamungkas, Rearrangement of administrative boundaries for reducing inner-city disparity case study of Tanjung Pinang city, Indonesia, in Journal of Urban and Regional Analysis, IX, 2, 113-128 (2017).

[7] F. Li, X. Liu, D. Hu, R. Wang, W. Yang, D. Li, D. Zhao, Measurement indicators and an evaluation approach for assessing urban sustainable development: A case study for China's Jining City, in Landscape And Urban Planning, 90, 3-4, 134-142 (2009). DOI: 10.1016/j.landurbplan.2008.10.022.

[8] S.A. Timashev, V.N. Alekhin, L.V. Poluyan, I. Fontanals, A. Gheorghe, Transforming Yekaterinburg into a Safe, Resilient-Smart and 
Sustainable City, IOP Conference Series: Earth and Environmental Science, IOP Publishing, 177, 1 (2018). DOI: 10.1088/17551315/177/1/012001.

[9] K. Spiekermann, M. Wegener, Modelling Urban Sustainability, in International Journal of Urban Sciences, 7, 1, 47-64 (2003).

[10] UCI Launch 2016, Urban Sustainability Index (USI) Report [Electronic resource]. Available at: http://www.urban china initiative.org/en/content/details_19_62344.html.

[11] U.V. Kataeva, A.V. Lapin, Formation of a methodical approach to the integrated assessment of the quality of the urban environment, in Bulletin of Perm University, Russia, 2, 21, 31-39 (2014).

[12] G. Alibekova, A. Panzabekova, Z. Satpayeva, N. Abilkayir, Sustainable development issues of Almaty as the largest metropolis in Central Asia, IOP Conference Series: Earth and Environmental Science, IOP Publishing, 177, 1 (2018). DOI: 10.1088/1755-1315/177/1/012010.

[13] City Prosperity Index Methodology and Metadata, UN Habitat (2016) [Electronic resource]. Available at: https://unhabitat.org/wpcontent/uploads/2019/02/CPI-

METADATA.2016.pdf.

[14] L-Y. Shen, J.J. Ochoa, M.N. Shah, X. Zhang, The application of urban sustainability indicators - A comparison between various practices, in Habitat International, 35, 1, 17-29 (2011). DOI: 10.1016/j.habitatint.2010.03.006.

[15] K. Mori, T. Yamashita, Methodological framework of sustainability assessment in City Sustainability Index (CSI): A concept of constraint and maximisation indicators, in Habitat International, 45, 1, 10-14 (2015).

[16] K. Mori, A. Christodoulou, Review of sustainability indices and indicators: Towards a new City Sustainability Index (CSI), in Environmental Impact Assessment Review, 32, 1, 94-106 (2012). DOI: 10.1016/j.eiar.2011.06.001.

[17] T. Lützkendorf, M. Balouktsi, Assessing a Sustainable Urban Development: Typology of Indicators and Sources of Information, in Procedia Environmental Sciences, 38, 546-553 (2017). DOI:10.1016/j.proenv.2017.03.122.

[18] J.M. Klopp, D.L. Petretta, The urban sustainable development goal: Indicators, complexity and the politics of measuring cities in Cities, 63, 92-97 (2017). DOI: 10.1016/j.cities.2016.12.019.

[19] D.M. Suvorov, L.A. Suvorova, I.V. Pestova, T.V. Baibakova, The dynamic index of urban environment quality as a tool for sustainable urban development, IOP Conference Series: Earth and Environmental Science, IOP Publishing, 177, 1 (2018). DOI: $10.1088 / 1755$ 1315/177/1/012007.

[20] D.M. Suvorov, L.A. Suvorova, T.V. Baibakova, Urboecology Problems in Building the Quality Index of the Urban Environment and its Use for Assessing the Sustainable Development of Cities in Ecology and Industry of Russia, 23, 5, 67-71 (2019). DOI: 10.18412/1816-0395-2019-05-6771.

[21] L.A. Suvorova, T.A. Kodolova, Problems of Minimization of Inconsistencies in Securing Sustainable Urban Development, International Scientific and Practical Conference. Conference Series: Economics and National Economy Management: Genesis, Current State And Development Prospects, Russia, 1, 2, 118-122 (2018). 